\title{
Magnetic to the Core - communicating palaeomagnetism with hands-on activities
}

\author{
Annique van der Boon ${ }^{1, \text { a }}$, Andrew J. Biggin ${ }^{1}$, Greig A. Paterson ${ }^{1}$, and Janine L. Kavanagh ${ }^{1}$ \\ ${ }^{1}$ Department of Earth, Ocean and Ecological Sciences, University of Liverpool, Jane Herdman Building, \\ 4 Herdman Street, Liverpool L69 3GP, UK \\ ${ }^{a}$ now at: Centre for Earth Evolution and Dynamics, University of Oslo, ZEB building, \\ Sem Sælands vei 2A, 0371 Oslo, Norway
}

Correspondence: Annique van der Boon (avanderboon.work@gmail.com)

Received: 2 November 2021 - Discussion started: 9 November 2021

Revised: 26 January 2022 - Accepted: 1 February 2022 - Published: 7 March 2022

Abstract. Palaeomagnetism is a relatively unknown part of Earth sciences that is not well integrated into the school curriculum in the UK. Throughout recent years, there has been a decline in the number of Earth science students in the UK. In 2018 and 2019, we developed outreach activities and resources to introduce the scientifically engaged general public to palaeomagnetism and raise awareness of how geomagnetism affects society today, thus putting palaeomagnetism, and Earth sciences, in the spotlight. We tested our ideas at local events that were visited mostly by families with small children, with tens to hundreds of participants. Our project culminated in the Magnetic to the Core stand at the Royal Society Summer Science Exhibition in 2019, which is visited by members of the general public, students and teachers, scientists, policymakers and the media. At this event, we communicated the fundamentals of palaeomagnetism through hands-on activities and presented our recent research advances in a fun and family- friendly way. To test the impact of our exhibit on knowledge of palaeomagnetism and Earth's magnetic field on visitors, we designed an interactive quiz and collected results from 382 participants over $8 \mathrm{~d}$. The results show a significant increase in median quiz score of $22.2 \%$ between those who had not yet visited the stand and those who had visited for more than $10 \mathrm{~min}$. The results from school-aged respondents alone show a larger increase in the median score of $33.5 \%$ between those who had not yet visited and those who had spent more than $10 \mathrm{~min}$ at the stand. These findings demonstrate that this outreach event was successful in impacting visitors' learning. We hope our Magnetic to the Core project can serve as an inspiration for other Earth science laboratories looking to engage a wide audience and measure the success and impact of their outreach activities.

\section{Introduction}

Palaeomagnetism is the field of research that deals with reconstructing the Earth's magnetic field in the past, as recorded by rocks. Palaeomagnetism is an important field of study through its relevance to the ongoing geomagnetic protection of Earth from space weather. Severe space weather is named by the UK government as being one of the major risks to society (National Risk Register, 2022). Palaeomagnetism is also important for its utility in solving geologic problems and has provided some of the first independent evidence for the theory of plate tectonics in the 1960s. Important contributions were made to the emerging field of palaeomagnetism in the UK in the 1950s (Merrill et al., 1998). There is, however, little awareness in the UK public of palaeomagnetism and its uses and benefits.

Palaeomagnetism is a truly multifaceted field as it bears upon all the natural sciences; it provides excellent possibilities for contributing to teaching in schools, with links to physics (magnetism), chemistry (composition of magnetic materials), mathematics (trigonometry and vector calculus), geography (plate tectonics), and biology (magnetotactic bacteria). At its heart, palaeomagnetism is a geoscience discipline, incorporating geophysics, geology, and physical geography. While geography is taught widely in UK schools, the availability of geology is much more patchy, and the 
number of courses is declining (Boatright et al., 2019). The number of A-level students (A-levels are UK secondary education qualifications, typically taken prior to university entrance) roughly halved since the 1980 s (peak at nearly 4000 entries), with a recent drop from 2500 to 1500 from 2014 to 2018. Geophysics is not taught until university level, although plate tectonics and other aspects of Earth science are taught within the national curriculum under geography and science. From 2017 to 2019, the number of geology students at UK universities decreased around $10 \%$ yearly (Boatright et al., 2019); thus, the need to increase awareness of the importance of Earth sciences to society among school students and their parents is increasingly pressing. Geophysicists are named on the list of shortage occupations in the UK (Migration Advisory Committee, 2020). Although palaeomagnetism outreach happens on local, regional, and national levels, there is a scarcity of documentation on particular palaeomagnetism outreach events or activities (Ayala et al., 2021), and it is thus difficult to assess what palaeomagnetism outreach is being done around the world and how effective it is. Outreach is increasingly valued as an activity in which scientists should participate, and we show here that, with relatively little equipment, audiences can learn a lot about the Earth's magnetic field.

\section{The Royal Society Summer Science Exhibition}

The Summer Science Exhibition of the Royal Society dates back to 1778, when the president of the Royal Society started "conversaziones" in which fellows of the Royal Society could talk about their scientific work to members of the public. These events developed into the Summer Science Exhibition, which has been running in its current form for more than 30 years (Royal Society, https://royalsociety.org/science-events-and-lectures/2021/ summer-science-exhibition/, last access: 1 March 2022). The exhibition is held in the building of the Royal Society in central London, close to Buckingham Palace. It attracts thousands of visitors each year and runs for $7 \mathrm{~d}$, at least $8 \mathrm{~h}$ each day, and hosts 22 stands. Teams on a stand usually consist of 20-50 people, depending on the budget and number of collaborators. Often, teams put in proposals for a stand as a collaborative undertaking, with multiple universities or institutes being involved in a bid. In total, around 700 scientists present their work at the exhibit each year. For the 2019 edition, about one-third of the proposals were successful, and our stand was the only one dedicated to Earth science at the exhibition and the only one from the University of Liverpool.

\section{Magnetic to the Core}

We describe here the development of our palaeomagnetism outreach activities and resources, the reactions from participants, and our evaluation process and its results. Ultimately, these outreach activities formed part of the University of Liverpool's Research Excellence Framework (REF) 2021 submission, highlighting its perceived value as a professional activity. Our activities can easily be adapted and emulated to fit other countries, labs, and audiences. We present this project in the hope that it can serve as an inspiration for other groups to perform outreach with impact in palaeomagnetism and Earth sciences.

\subsection{Outreach team and training}

We formed a team that was diverse in terms of age, career stage, and gender. The team consisted of doctoral students (seven, of which two were women), postdocs (seven, four women), with the addition of Master of Science students (two, both women), a technician (man), a research fellow (man), senior lecturers (two, both women), and a professor (man). Actions such as using name badges with the option to include preferred pronouns would be one way, at future events, to publicly recognise gender as non-binary and, therefore, increase the inclusivity of the event with respect to gender identity. Unfortunately, the lack of racial diversity in Earth sciences (Bernard and Cooperdock, 2018; Dowey et al., 2021; Dutt, 2020), and palaeomagnetism in particular (Ayala et al., 2021), was also reflected in our team. In order to try and recruit team members from diverse backgrounds, we contacted other palaeomagnetic laboratories in the UK several months before the exhibition, and tried to enthuse (doctoral) students and researchers to join our team. Unfortunately, this yielded no results in terms of increased racial diversity, and we were thus unable to form a team that showed the same diversity as the UK society and the audience at the exhibition. This is problematic because when young people do not see palaeomagnetists (or scientists in general) who look and sound like them, then this gives the indirect impression that palaeomagnetism (or science) is not for them. Evidenced action lists to address the lack of diversity in geosciences, including marginalisation related to gender identity, ethnicity, sexuality, physical ability, socioeconomic background, and intersectionality, should be consulted when putting together teams that deliver outreach activities and the way the team and the resources they create are presented (e.g. Ali et al., 2021; Dowey et al., 2021; Kaaden et al., 2021; Núñez et al., 2020).

We developed our outreach activities over several months and tested our activities at smaller outreach events that attracted tens to hundreds of visitors, mostly families with young children. These smaller events were a good way to obtain some first experience in outreach for most team members and allowed us to judge which activities were most engaging. It was also a good way to form ideas about the knowledge levels of visitors and adapt our outreach to that and to try different strategies to measure the impact of our outreach.

Because of differences in backgrounds and level of experience in palaeomagnetism and outreach amongst our team 
members, we organised a day-long training session for everyone on the team for the Royal Society Summer Science Exhibition. This training session was, for a large part, based on the training day that the Royal Society provided for two members of each stand, which was given by the Science Museum Group. The training was adapted to provide a more standspecific training for our Magnetic to the Core team.

During the training, we invited the university press officer and social media officer to give presentations on how to talk to journalists and use social media during the exhibit. We developed a list of commonly used jargon in palaeomagnetism and came up with other terms that would be better suited to explain our science to people without a scientific background (see Table 1). We thought about what different kinds of visitors would like to take away from the experience and designed interactions suited to specific groups of visitors (kids, families, groups of friends, independent adults, etc.). We then role-played short $(2-3 \mathrm{~min})$ interactions with different groups of visitors so that our team members became proficient in engaging in a fun way with visitors, while also bringing across the key messages of our stand. The interactions were designed using a framework for engagement that consisted of four phases. The first phase is the "hook", in which we drew the attention of a visitor and tried to make them engaged (e.g. asking "Would you like to do an experiment?"). Subsequently, we would "inform" the visitor, by introducing ourselves and showing or explaining something to them. Then, we would "enable" the visitor, often by having them do a hands-on activity. Finally, the interaction would end with "extending" the experience, in which we would give them something to take home or show how what they had learnt linked to their daily lives. This framework was particularly useful because it showed a clear beginning and end to interactions and enabled us to bring across our key messages in an engaging way, while only taking a few minutes. The framework made it easy for visitors to walk on to the next stand after a few minutes or stay longer if they were interested in knowing more.

During the training, we discussed good and bad interactions, and practised having a two-way conversation with visitors. We practised encouraging visitors to ask questions, instead of providing them with information in a one-way interaction. We also practised and discussed difficult scenarios (see File S1 in the Supplement), to ensure the safety of both our visitors and team members. The scenarios we practised involved interactions that did not go as planned, so each team member would know what to do when things (or interactions) went wrong, and who to ask for help.

\subsection{Scientific content and learning outcomes}

We developed a range of activities that were centred on the research tools of palaeomagnetists and invited visitors to experience what it is like to be a palaeomagnetist. The tasks were related to some fundamental paleomagnetic work, and the team members could easily form links to their own research when interacting with visitors.

We trained our team in communicating science to lay audiences, where we focused on the following three key messages:

1. Earth has a magnetic field that acts as an invisible shield that protects us from space weather.

2. Palaeomagnetism is the study of the ancient magnetic field in rocks and anyone can do it.

3. Palaeomagnetism tells us about how the inside and outside of Earth have changed in the past and how they might change in the future.

Interactions were designed to convey one or more of these key messages via learning outcomes. The learning outcomes are the messages that we wanted our audience to realise and remember after visiting our stand. The four learning outcomes were as follows:

1. Rocks are cool, and they can record magnetic fields.

2. The magnetic poles of Earth reverse.

3. Different materials have different magnetic properties.

4. Palaeomagnetism is practical, hands-on, and anyone can do it.

Defining the learning outcomes enabled the evaluation of the outreach activity, and we designed our hands-on activities so that they all related to one or more learning outcomes (see Table 2). The use of learning outcomes allowed us to test whether visitors had learnt something new about palaeomagnetism from visiting the stand.

\subsection{Hands-on activities}

There was a logical order to the activities in our stand (see Fig. 1), although they could all be enjoyed separately without previous knowledge acquired through the other activities or prior knowledge of palaeomagnetism. The logical order that we chose follows the path that a student who applies palaeomagnetism in a research project usually takes. (1) Without a lot of prior knowledge on palaeomagnetism, students go on fieldwork to collect samples. (2) Students then measure samples to determine the direction of Earth's magnetic field when the rock formed and learn to interpret the results. (3) Students do additional rock magnetic measurements that give information on the magnetic minerals present in the samples. (4) Students then go on to learn more about the fundamentals of palaeomagnetism to put their results into a wider scientific context. Most of the hands-on activities benefit visual and kinesthetic learning preferences (https://vark-learn.com/, last access: 24 February 2022). The interaction with team members at the stand catered for visitors with an aural learning 
Table 1. Scientific jargon and plain language alternative terminology.

\begin{tabular}{ll}
\hline Scientific jargon & Alternative terminology \\
\hline (Geo)dynamo & Magnetic field (generator) \\
Sample & Piece of rock \\
Specimen & Piece of rock \\
Palaeomagnetism & Study of the magnetic field in the past \\
Magnetometer & Machine that measures a magnetic field \\
Modelling & Computer modelling \\
Simulation & Computer model \\
Magnetostratigraphy & Record of the magnetic field in the past \\
Magnetic susceptibility & How magnetic something becomes \\
Remanence & Magnetic memory \\
Reversal & Magnetic pole flip/compass points the other way \\
Polarity & Direction (north/south) that the compass needle points \\
(Outer) core & Engine of the magnetic field inside the Earth \\
Mantle & Inside of the Earth \\
Dipole & Bar magnet \\
Quadrupole & Complex magnet \\
Space weather & Particles from the Sun \\
Mineral & Particle in a rock \\
Anomaly & Weird spot \\
\hline
\end{tabular}

Table 2. Overview of the relation between hands-on activities, key messages, learning outcomes, and learning preferences. Note: VARK - visual, aural, read/write, kinesthetic.

\begin{tabular}{lrrl}
\hline Name of activity & $\begin{array}{r}\text { Key } \\
\text { message }\end{array}$ & $\begin{array}{r}\text { Learning } \\
\text { outcome }\end{array}$ & VARK \\
\hline Licence to drill & 2 & 4 & $\mathrm{~V}, \mathrm{~K}$ \\
Kickstool magnetometer & 2,3 & $1,2,4$ & $\mathrm{~K}$ \\
Rock or choc & 2 & 3 & $\mathrm{~K}$ \\
Magnetic globe & 1,3 & 2 & $\mathrm{~V}$ \\
\hline
\end{tabular}

preference (who prefer discussions and stories). The backdrop of our stand catered to visitors who had a learning preference for reading (see also Table 2).

\subsubsection{Experiencing sample collection}

Palaeomagnetic studies often start out with sample collection. In order to translate taking paleomagnetic samples in the field to an activity that could be done indoors, we had a gasoline-powered drill with a printed background of rocks in the high Arctic that was part of the research conducted by a team member (Bono et al., 2013). For safety, the drill was drained of fuel and cleaned so it could not be turned on, and it was secured to the stand with high-strength steel cables (see Fig. 1). Visitors could then pose for a picture with the drill, dressing up in high-visibility vests and a hard hat, emphasising that safety is an important component to fieldwork.

This activity was tied to Learning Outcome (LO) 4 and demonstrated that palaeomagnetism is practical, hands-on, and anyone can do it, in the sense that taking samples in the field is a practical exercise that requires little previous knowledge. Fieldwork is a favourite part of the job for many palaeomagnetists. This activity shows that science can be fun and can take you to some of the most stunning places on Earth.

\subsubsection{Measuring samples}

The visitors could then go on to measure samples that they had just taken. We provided a set of lava from Iceland, which visitors could measure on the kickstool magnetometer (see Fig. 2). This magnetometer, designed in collaboration with Magnetic Measurements (http://www. magnetic-measurements.com/, last access: 24 February 2022), was built specifically for outreach, with the name coming from the low-cost kickstool that forms the main frame of the system. The magnetometer is connected to a screen that shows the polarity of the lava samples. Half of the samples had a normal polarity (i.e. corresponding to an Earth magnetic field in which the magnetic poles are in the same position as today), while the other half of the samples had a reverse polarity (i.e. the magnetic poles were in a reversed position from today's field).

This activity was tied to LOs 1, 2, and 4. Visitors could hold the rocks, place them in the sample holder, operate the magnetometer themselves, and deduce the polarity of the rocks. We explained to visitors during this activity that the last time Earth's magnetic field was reversed was around $780 \mathrm{ka}$, so the rocks for which they measured a reverse polarity must be at least 780000 years old. 


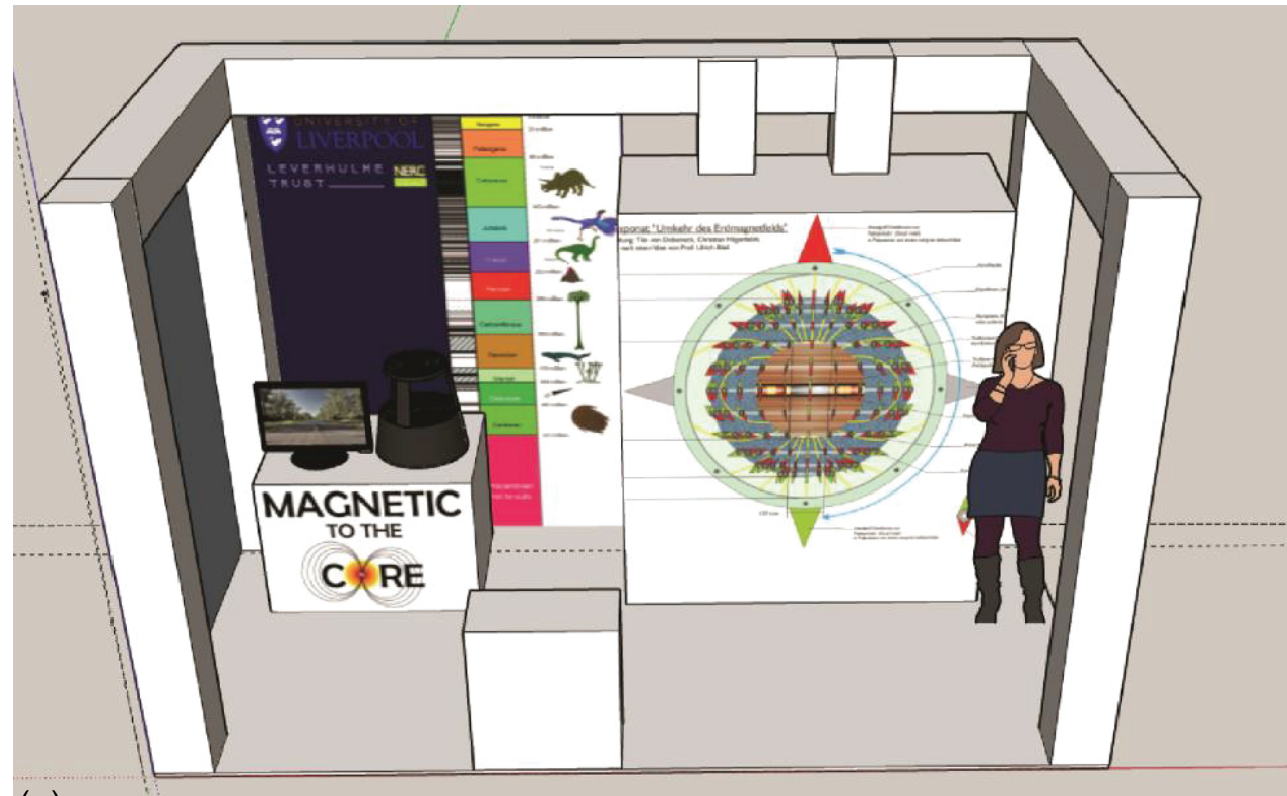

(a)

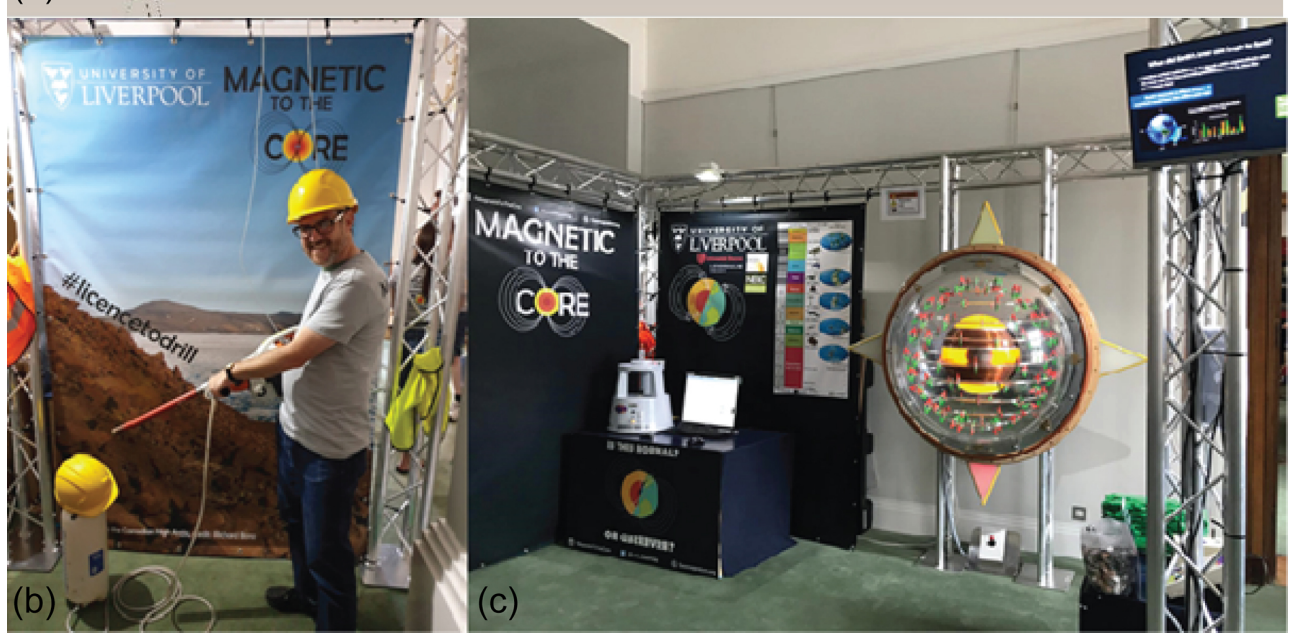

Figure 1. (a) Preliminary design of the stand in SketchUp; the size of the entire stand is $4 \mathrm{~m} \times 2 \mathrm{~m}$. (b) Andy Biggin receiving his license to drill. (c) The Magnetic to the Core stand at the Royal Society Summer Science Exhibition, 2019. On the left is the kickstool magnetometer, in the centre is the magnetic globe, and rock or choc is on the right. The license to drill is on the far left of this image, behind the Magnetic to the Core banner.

\subsubsection{Rock or choc}

Rock or choc proved to be the most popular activity, as it was open to all ages, there was a gaming element to it, and visitors were given a chocolate pebble as a reward for their participation. Using the concept of magnetic susceptibility, which demonstrated LO 3 (different materials have different magnetic properties), visitors could distinguish real rock pebbles from chocolate pebbles (see Fig. 3). The real rock pebbles were black decorative basalt pebbles that are often used in aquariums and have a high magnetic susceptibility. We gave visitors a set of pebbles in clear plastic boxes that could not be opened, and asked them to distinguish the real pebbles from the chocolate pebbles. Half of the pebbles were real rocks, and the other half were chocolate. Visitors could try to distinguish them by visual inspection, weighing the boxes in their hands, and shaking the boxes. Although the weight of the real pebbles was slightly larger than that of the chocolate pebbles, it was nearly impossible to distinguish them. Visitors could then check if they had guessed correctly which pebbles were real rocks by placing them in a Bartington MS2 susceptibility meter. Because rocks contain magnetic minerals, they have a high magnetic susceptibility and gave high values on the susceptibility meter. Chocolate is not magnetic, so the chocolate pebbles gave magnetic susceptibility values of around zero. As a reward for participating, we gave visitors a chocolate pebble that they could eat at the end of this 


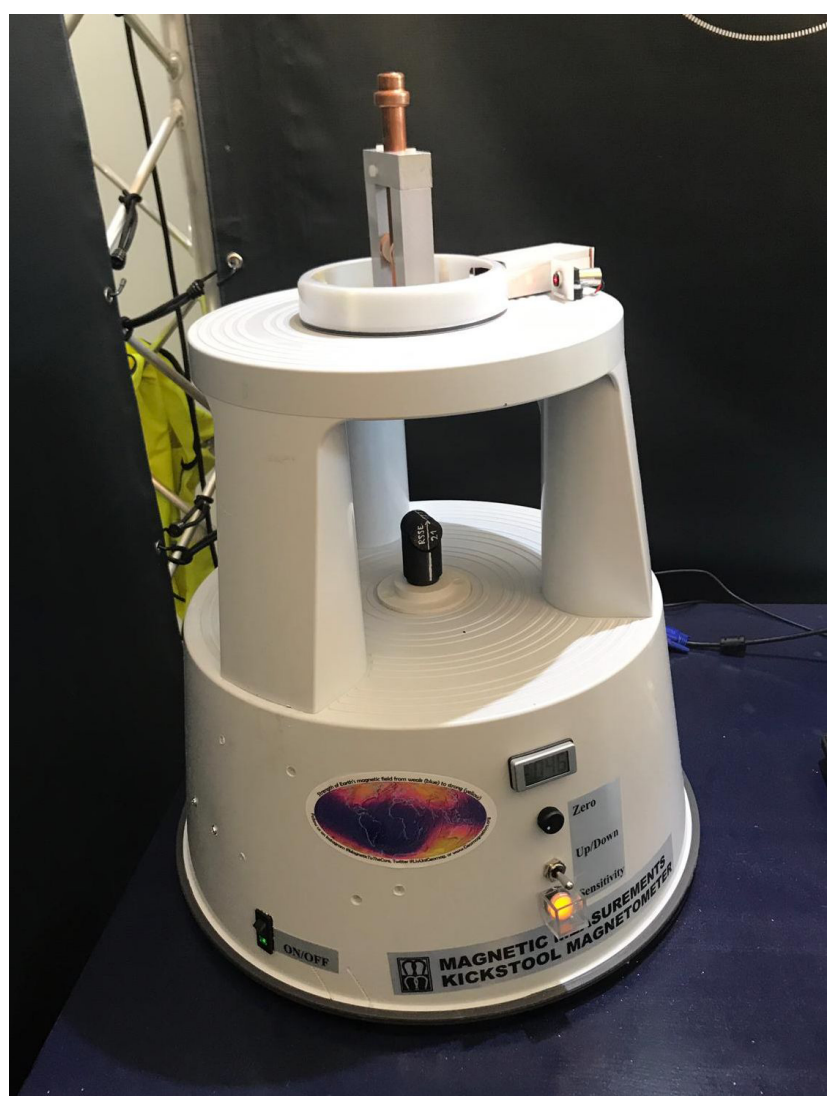

Figure 2. The kickstool magnetometer.

activity. As part of our signage, appropriate allergen information was provided. Alternatively, this activity can be carried out using a compass, which will show deflection of the needle when brought close to a magnetic rock pebble. The chocolate pebbles will not show a deflection of the compass needle.

\subsubsection{Magnetic globe}

Next, visitors could learn about the reversing magnetic field by simulating a polarity reversal in a scaled model of Earth's magnetic field and dynamo (see Fig. 4). This model was borrowed from the paleomagnetic laboratory at the University of Bremen, where the globe was designed and built. The globe contains a solid iron ball in the middle, which represents the solid inner core. Around this iron ball is a copper coil, which generates a magnetic field when a current is running through it. This coil represents the liquid outer core of the field, which is where Earth's magnetic field is generated. The mantle was represented by empty space, and small magnetic compasses were placed at a scaled distance to represent the Earth's crust. The globe could simulate a reversal by flipping a switch on the controller, which made the field go from a dipolar state to a quadrupolar state. This was visualised by the magnetic compasses, which changed orientation in response to the changing field. Pushing the switch further made the field flip from a quadrupolar state back to the dipolar state in the opposite polarity as before. This activity was tied to LO 2 (the poles of Earth's magnetic field reverse). A low-budget version of this activity can be made using a bar magnet and a set of compasses positioned around the bar magnet, although it would not be possible to image the quadrupolar state this way.

\subsection{Screen, posters, social media, and freebies}

If it was busy at the stand, visitors sometimes had to wait for their turn to participate in the hands-on activities. To keep them engaged, we had a screen at the stand that showed summaries of each team member's research, as well as short videos of fieldwork. To extend the stand visit beyond the exhibition, we had two freebies for visitors (see Fig. 5). One was a sticker with a map of the Earth and the magnetic field strength, with the social media details of our stand and group. Another was a fridge magnet that shows a plate tectonic reconstruction of Earth at $250 \mathrm{Ma}$ (Torsvik et al., 2012), which could only be obtained through participation in the quiz. We also made printed booklets with 10 facts about palaeomagnetism, called "Ten things you might not know about Earth's magnetic field" (van der Boon, 2019).

\subsection{Quiz}

To evaluate what visitors had learnt from visiting our stand, we designed a multiple choice quiz, and we rewarded their participation with a fridge magnet. The quiz consisted of nine questions about palaeomagnetism and five questions related to visitors' background and their experience at the stand (see File S2).

Trained stand exhibitors used a tablet and the QuickTapSurvey (https://www.quicktapsurvey.com/, last access: 24 February 2022) app to evaluate the knowledge of people who had visited the stand for more than 10 min, less than $10 \mathrm{~min}$, and those who had not yet visited the stand. The quiz was designed to assess the impact of the stand on visitors' ability to answer questions related to the learning outcomes. The quiz was a fun way to assess people's knowledge, and participants were generally very willing to take part. We also asked visitors whether they were in school, as this allowed us to roughly assess their age without collecting sensitive information. During the exhibition, there was one person at the stand at all times whose goal was to approach people to do the quiz. This team member would ask the questions to visitors and fill in the answers on a tablet. We trialled other approaches with questionnaires that visitors could fill in themselves at smaller outreach events, but this method was unsuccessful, as visitors were generally not very eager to fill in a questionnaire or would only fill in half the answers. 


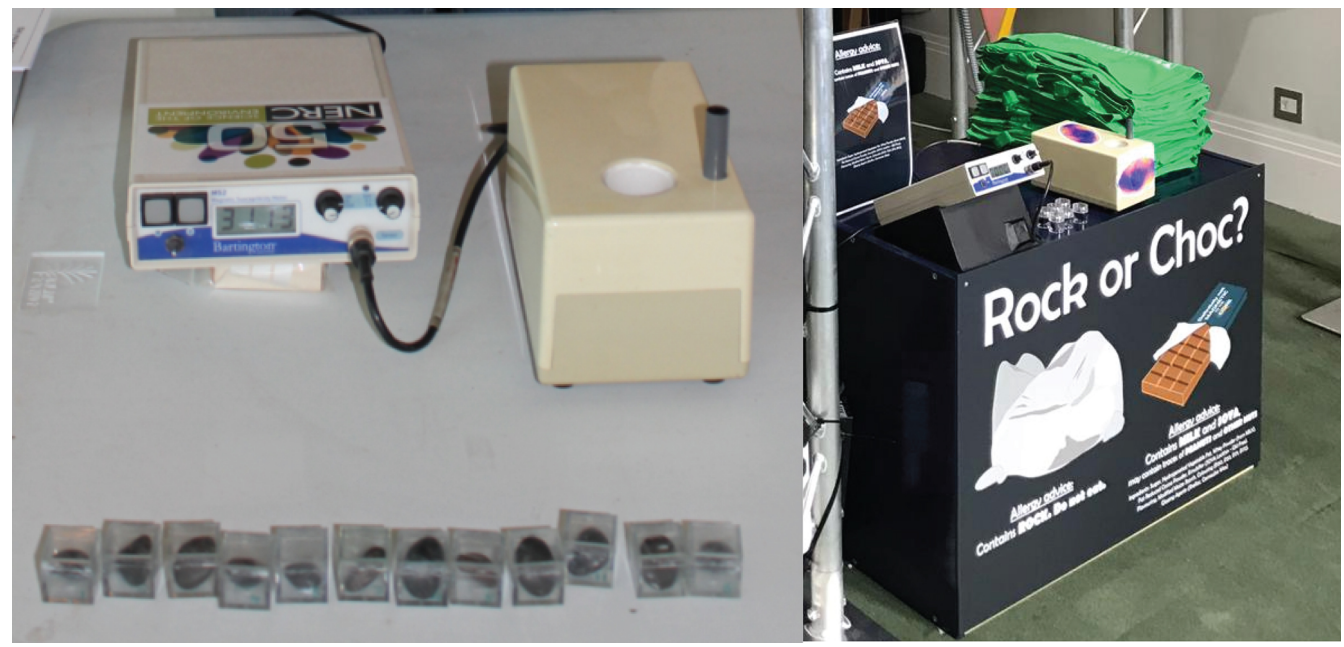

Figure 3. Rock or choc set-up, with boxes of chocolate and rock pebbles, and a Bartington susceptibility meter.

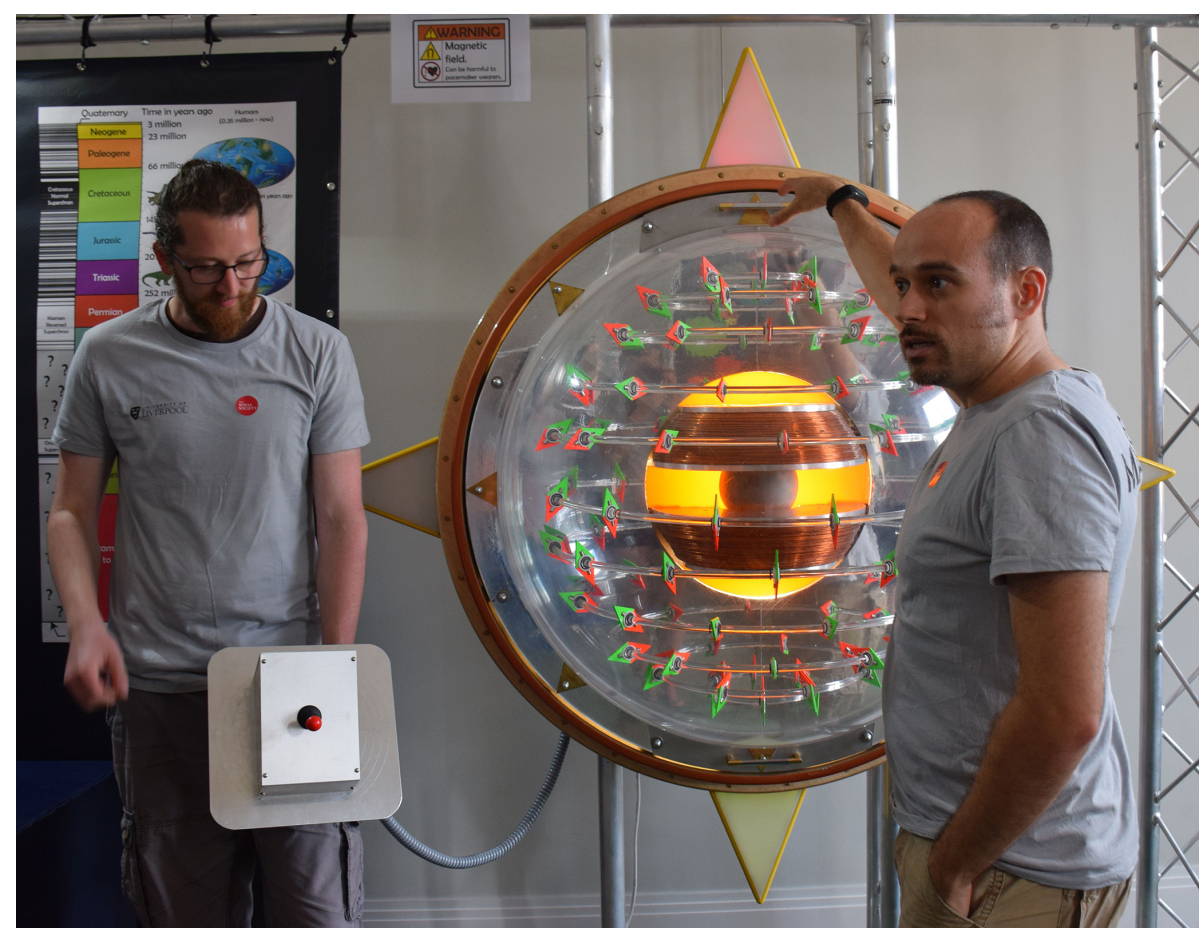

Figure 4. Daniele Thallner and Greig Paterson with the magnetic globe and switch.

\section{Ethics}

Ethical considerations were taken into account before gathering the data, and the study was approved by an ethics panel at the University of Liverpool. The data collection was designed so that individuals could not be identified, and no sensitive information was collected from participants (following the General Data Protection Regulation - GDPR). This, however, limited the options for assessing the long-term impact of the stand on participants, as a follow-up study of the same group of individuals was not possible.

\subsection{Budget}

Doing outreach events effectively can be an expensive undertaking. To make the costs of doing a large outreach event insightful, we provide the generalised budget for the Magnetic to the Core project (see Table 3) to help guide the plans of other groups with future outreach activities. We were able to secure a total of GBP 24000 for our stand. Most of the budget was provided by the University of Liverpool, and another significant part came from research budgets of grants awarded to the research group from Leverhulme and the Natural En- 

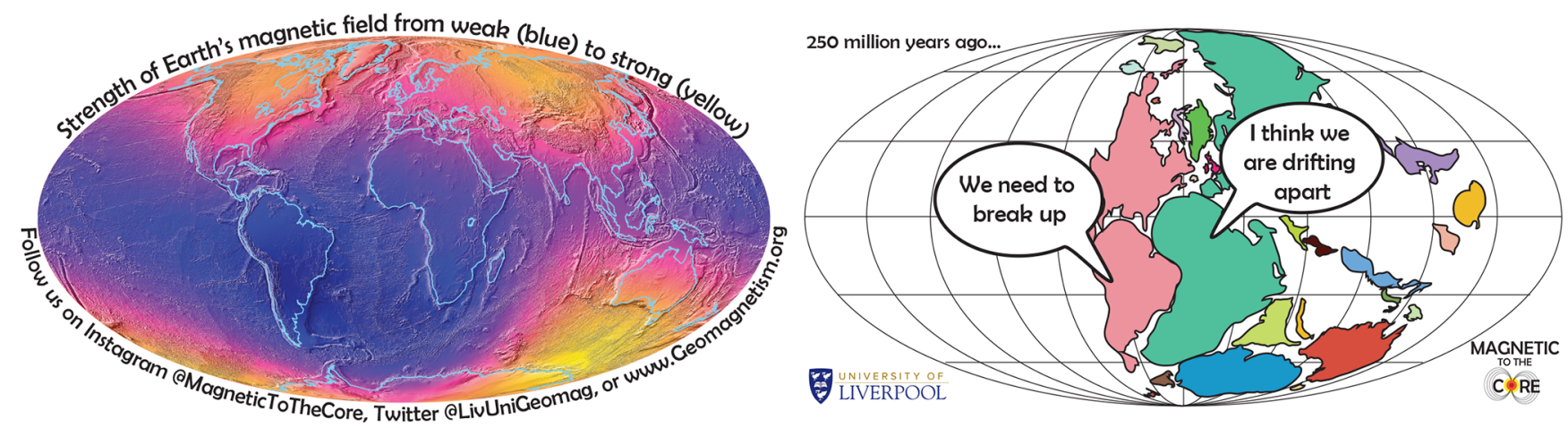

Figure 5. The sticker (left), with links to websites (http://www.geomagnetism.org/) and social media, and a fridge magnet (right) that were handed out to visitors of the stand.

vironment Research Council (NERC). Smaller amounts of funding were provided by the Royal Society and British Geophysical Association. Applications to four other grants to fund team members' participation in the exhibition, worth a total of GBP 4500, were unfortunately all unsuccessful. Our experiences here highlight the continued problematic nature of obtaining funding for outreach and public engagement, despite a professed eagerness from funding agencies to support these efforts and recognition of the significant gains that can be achieved. Scientists are often expected to develop and do outreach on top of their research and teaching, while outreach projects like Magnetic to the Core take a serious amount of time and dedication. Having a 2-month, full-time postdoc leading the project was a bare minimum for the scale of this undertaking.

Most of the costs of the project went into transporting the 21 people on our team to London and providing accommodation there for $10 \mathrm{~d}$. Team members stayed in shared accommodation booked through Airbnb and had an allowance of GBP 15 per day for food. Another significant cost was the salary of the first author of this paper, who was employed as a postdoctoral researcher to manage the project full-time for 2 months. Although it is difficult to estimate the true cost that also takes into account any hidden costs, just the number of hours spent at the stand during the exhibition is around 450. This does not include any preparation, travel, build-up, or taking down of the stand. We estimate that taking into account all the hours that all team members worked in total would probably put the true cost at double the amount that our budget shows.

\section{Results}

Over the course of $7 d$, the Royal Society Summer Science Exhibition, which featured 22 stands, attracted a total of 12653 visitors. This included 1518 students and 187 teachers from 89 schools.

\subsection{Number of visitor interactions}

We had several ways to obtain estimates of the number of visitors to the stand. One was through the number of freebies. We printed 1000 stickers, which were all handed out after day 4 of the exhibition. However, some groups of people would go on the hunt for freebies without visiting the stand, making this an overestimate of the number of visitors. To measure the number of visitor interactions at our stand specifically, the number of kickstool magnetometer measurements was used as a proxy. The results show that over the course of the week, 1011 measurements were recorded (see Fig. 6). Generally, participants measured between two and six samples, putting the estimate of the number of people using the kickstool magnetometer at between 170 and 500 . Figure 1 shows the number of measurements performed per day. Not all visitors used the magnetometer, so the number of attendees to the stand as a whole was much higher. We registered 382 quiz responses, of which 165 had already visited the stand. In total, we estimate that at least several hundred and possibly 1000 visitors interacted with our stand.

\subsection{Impact on knowledge of visitors}

The impact of this outreach event on the knowledge of visitors was measured by looking at the difference in quiz scores between participants who had and had not (yet) visited the stand. Because the data do not show a normal distribution, we use median values instead of averages. In total, there were 382 quiz responses recorded, of which 136 were by schoolaged participants (see Table 4). As shown in Fig. 7, the median quiz scores increased by $11.1 \%$ for those who visited the stand for less than 10 min compared with those who had not yet visited the stand. For those who visited the stand for more than $10 \mathrm{~min}$, their median scores increased by $22.2 \%$.

Comparatively, visitors of school age who visited the stand for an extended period of time experienced a more significant increase in the accuracy of their scores in the quiz (see Fig. 7). School-aged participants who visited the stand for less than 10 min achieved a $22.3 \%$ increase in median scores 
Table 3. Indicative budget and costs of the Magnetic to the Core project.

\begin{tabular}{ll|ll}
\hline Amount in & From & Amount out & What \\
\hline GBP 10 000 & $\begin{array}{l}\text { University of Liverpool, School of Environmental } \\
\text { Sciences }\end{array}$ & GBP 5500 & Costs for building stand and all materials \\
\hline GBP 10 000 & $\begin{array}{l}\text { University of Liverpool, Faculty of Science and En- } \\
\text { gineering }\end{array}$ & GBP 7500 & $\begin{array}{l}\text { Costs for accommodation and food for } \\
\text { the team }\end{array}$ \\
\hline GBP 3350 & $\begin{array}{l}\text { Contribution from existing research grants (funded } \\
\text { by the Leverhulme Trust and NERC) }\end{array}$ & GBP 5000 & Costs for transport to and from London \\
\hline GBP 400 & Royal Society & GBP 6000 & A 2-month, full-time postdoc salary \\
\hline GBP 250 & British Geophysical Association & GBP 24000 & Total \\
\hline GBP 24 000 & & &
\end{tabular}

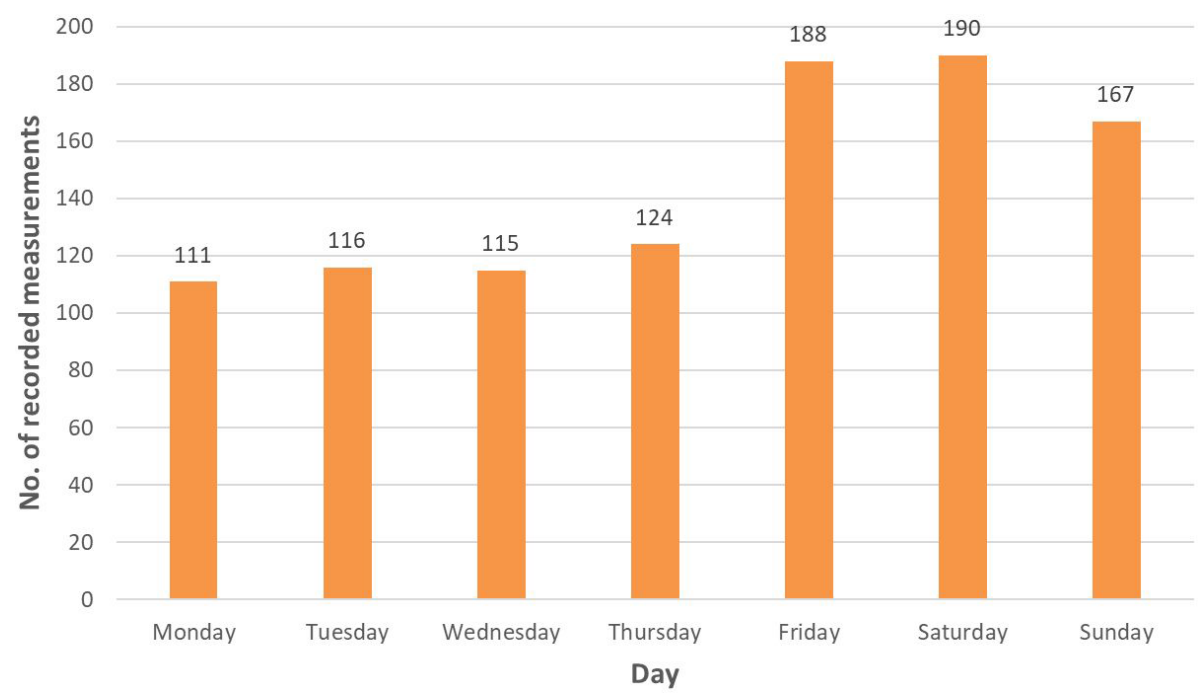

Figure 6. Number of measurements performed on the kickstool magnetometer per day.

Table 4. Number of quiz responses.

\begin{tabular}{lrrrr}
\hline & $\begin{array}{r}\text { Not } \\
\text { visited }\end{array}$ & $<10$ min & $>10$ min & Total \\
\hline All participants & 216 & 77 & 89 & 382 \\
\hline $\begin{array}{l}\text { School-aged } \\
\text { participants }\end{array}$ & 66 & 36 & 34 & 136 \\
\hline
\end{tabular}

compared to school-aged participants who had not yet visited the stand. School-aged participants who visited the stand for more than 10 min experienced a $33.5 \%$ increase in their median scores compared to those who had not yet visited. We use the Wilcoxon rank sum test for common medians (also known as the Mann-Whitney test). Comparing the responses from people who had not yet visited the stand to people who had visited $<10$ min yields Wilcoxon rank sum $p$ values of $p=0.010$ for all respondents and $p=0.003$ for school-aged respondents. Comparing the $<10$ min responses to the $>10 \mathrm{~min}$ responses gives the following $p$ values for the tests: $p \ll 0.001$ - all respondents; $p=0.004-$ schoolaged respondents. In both cases, at better than the $0.5 \%$ confidence level, we can reject the null hypothesis that the responses from the different groups come from distributions with the same median. Thus, the differences are significant. Performing a two-sample $t$ test (for equal means) on average scores (which ignores the non-normality of the data) also shows there is a significant increase in quiz score.

The answers to the question "Can you tell us one thing you have learnt from the stand?" show that we were successful with regards to bringing across our learning outcomes. There are 210 answers to this question (see File S2 in the Supplement), with 89 of these answers specifically relating to a learning outcome. Of these, 19 mention LO 1 in some form (e.g. "measuring polarity with magnetometer"), 61 mention LO 2 (e.g. "magnetic reversals"), 7 mention LO 3 (e.g. "chocolate is not magnetic"), and 2 mention LO 4 (e.g. 


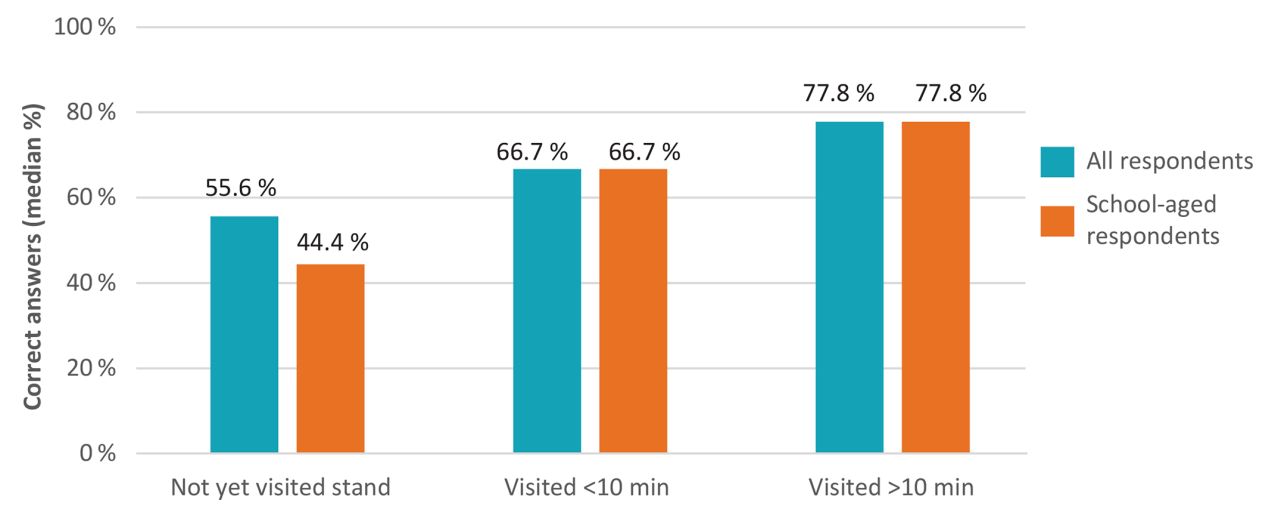

Figure 7. Median quiz scores.

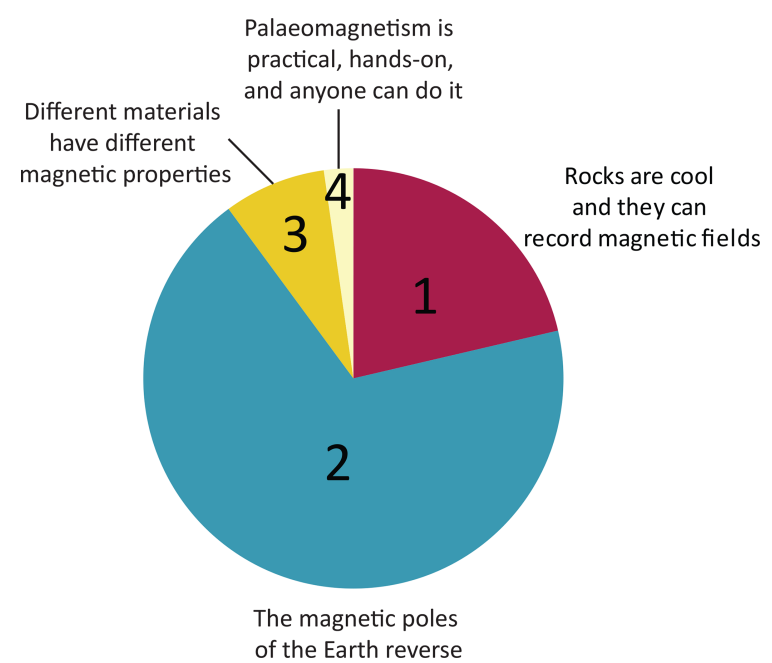

Figure 8. Learning outcomes (LOs) mentioned by participants as the things they had learnt. LO 1 - rocks are cool, and they can record magnetic fields. LO 2 - the magnetic poles of the Earth reverse. LO 3 - different materials have different magnetic properties. LO 4 - palaeomagnetism is practical, hands-on, and anyone can do it.

"that samples are taken by drilling"; see Fig. 8). Another theme that is often mentioned is that the Earth's magnetic field is generated in the (liquid outer) core. Although, not specifically linked to a learning outcome, this was often discussed with visitors interacting with the magnetic globe. A common theme emerging from the answers not linked to a learning outcome is the deep Earth (e.g. "the Earth has a solid core" and "liquid outer core").

\section{Discussion}

Our results indicate that our stand had an impact on visitors' knowledge regarding palaeomagnetism and the Earth's magnetic field. One of the downsides of our approach, in which there was one team member who asked the questions and filled them in on a tablet, was that we were often dealing with groups of people instead of individuals. Some groups wanted to do the quiz together as a team, and they would discuss amongst themselves which the most likely answer was. Other groups of people wanted to do the quiz as opponents, while it was only possible to fill in one answer at a time. The quiz thus only gives a rough indication of the impact of our stand on the knowledge of visitors. Furthermore, our question "Can you name one thing you learnt from the stand?", which was a good way to test if our learning outcomes had come across, often took a long time to fill in on the tablet. This led, in some cases, to incomplete answers, particularly when it was busy at the stand and people were queuing for the quiz. We trialled a different approach at the smaller outreach events, which was to let visitors fill this in themselves on a piece of paper. This, however, turned out not to be a good alternative, as visitors often left that box blank. Thematic analysis (Braun and Clarke, 2006) can be used to evaluate answers from this type of open question. Although rock or choc was extremely popular, visitors do not often refer to LO 3, possibly because it is considered common knowledge. We do note that there are many answers along the lines of "chocolate can look like a rock", but we did not count these in our analysis because they do not specifically mention magnetism.

It is unclear if the targeted group is representative for society as a whole, as the prestige of this event and the location could have attracted attendees from more affluent backgrounds. The participants may represent a well-educated proportion of the general public, perhaps with prior general knowledge about science, thus making participants more familiar with scientific topics than the general population. The Royal Society arranged participation for school groups, specifically aimed at schools from the least affluent areas to mitigate this for part of our studied demographic, i.e. the school-aged participants.

Due to the barriers on collecting sensitive information (such as gender, age, contact details, etc.), we are unable to provide more specific details about the participants to the 
study. Our team members that were in charge of the questionnaires aimed to question an even spread of school-aged participants and non-school-aged participants and people who had and had not yet visited the stand.

The adults who attended the exhibit were self-selecting, making it likely that they had a general interest in science prior to the exhibition. This is inferred by all respondents receiving a median score of $55.6 \%$, despite not having visited the stand yet, and school-aged respondents receiving $44.4 \%$ median scores when not having visited the stand yet. Therefore, collecting another dataset in a different location may be beneficial to see whether these results are representative for the general public.

\section{Conclusions}

We have presented our Magnetic to the Core project here in the hope that it will inspire other researchers to undertake Earth science outreach. Despite having a relatively small budget (GBP 24000 ) and little prior experience of major outreach activities amongst the team members, the Magnetic to the Core stand at the Royal Society Summer Science Exhibition 2019 was successful in achieving its aims and provided tangible benefits to the team and funders, as well as the public who attended it. We have provided an example of how to measure the impact of outreach events and share our budget and evaluation to demonstrate the actual cost and value of outreach activities. By using the recordings from the kickstool magnetometer and quiz responses, we estimate that at least several hundreds of visitors interacted with the stand. We show that visiting the stand had a measurable influence on visitors' knowledge of palaeomagnetism and the Earth's magnetic field through a significant increase in quiz scores. An increased amount of time at the stand increased the median scores further. In order to gain results that are representative of society as a whole, more data are needed to mitigate the self-selection of participants. Overall, our experiences with Magnetic to the Core were positive, with every team member expressing their enjoyment in participating. Although challenging at times, the events were rewarding and have strongly motivated us to continue our outreach efforts.

Data availability. All quiz answers are provided in File S2 in the Supplement. Supplementary data are available on GitHub (https://doi.org/10.5281/zenodo.6257839; Paterson, 2022).

Supplement. The supplement related to this article is available online at: https://doi.org/10.5194/gc-5-55-2022-supplement.
Author contributions. All authors participated in the design and execution of the project, and all authors were involved in the writing of the paper.

Competing interests. The contact author has declared that neither they nor their co-authors have any competing interests.

Disclaimer. Publisher's note: Copernicus Publications remains neutral with regard to jurisdictional claims in published maps and institutional affiliations.

Acknowledgements. The Magnetic to the Core project was partly funded by the Leverhulme Research Leadership award (grant no. RL-2016-080), the Natural Environment Research Council (NERC; grant nos. NE/P00170X/1, NE/S008330/1), all to Andrew J. Biggin, the NERC Independent Research Fellowship to Greig A. Paterson (grant no. NE/P017266/1), with additional funding from the University of Liverpool, the British Geophysical Association, and the Royal Society. JK acknowledges a UKRI Future Leaders Fellowship (MR/S035141/1). This work could not have been done without all of the hard work and enthusiasm of our team, consisting of Anouk Beniest (VU Amsterdam), Richard Bono, Yael Engbers, Michael Grappone, Ben Handford, Louise Hawkins, Mimi Hill, Elliot Hurst, Tereza Kamenikova (University of Lancaster), Simon Lloyd, Domenico Meduri, Joe Perkins (Imperial College London), Georgia Quinn, Jenny Schauroth, Courtney Sprain, and Daniele Thallner. We thank the team at the Royal Society and Amy Fry, in particular, for their help, enthusiasm, and organisation. We benefited a lot from the training provided by the Science Museum. We thank all visitors of our stand for their interest in our research and their questions, the Paleomagnetic Laboratory of the University of Bremen, for lending us the magnetic globe, and Emma Goult, for processing our survey results. We thank Rosella Nave, an anonymous reviewer, Faye Nelson, and editor Solmaz Mohadjer, for their comments that have improved the paper.

Financial support. This research has been supported by the Leverhulme Trust (grant no. RL-2016-080), the Natural Environment Research Council (grant nos. NE/P00170X/1, NE/P017266/1, and NE/S008330/1), and UKRI Future Leaders Fellowship (MR/S035141/1)

Review statement. This paper was edited by Solmaz Mohadjer and reviewed by Rosella Nave and one anonymous referee.

\section{References}

Ali, H. N., Sheffield, S. L., Bauer, J. E., Caballero-Gill, R. P., Gasparini, N. M., Libarkin, J., Gonzales, K. K., Willenbring, J., Amir-Lin, E., Cisneros, J., Desai, D., Erwin, M., Gallant, E., Gomez, K. J., Keisling, B. A., Mahon, R., Marín-Spiotta, E., Welcome, L., and Schneider, B.: An actionable anti-racism 
plan for geoscience organizations, Nat. Commun., 12, 1-6, https://doi.org/10.1038/s41467-021-23936-w, 2021.

Ayala, C., Beamud, B., Huebert, J., Jones, S. A., Kumar, A., Miller, S. R., Moorkamp, M., Pueyo, E. L., RuizConstan, A., Schamuells, N., Sur, D., Tauxe, L., and van Hinsbergen, D. J. J.: Geomagnetism, Paleomagnetism and Electromagnetism Perspectives on Integrated, Coordinated, Open, Networked (ICON) Science, ESSOAr, 249-252, https://doi.org/10.1002/essoar.10508852.3, 2021.

Bernard, R. E. and Cooperdock, E. H. G.: No progress on diversity in 40 years, Nat. Geosci., 11, 292-295, https://doi.org/10.1038/s41561-018-0116-6, 2018.

Boatright, D., Davies-Vollum, S., and King, C., Earth science education: The current state of play. Geoscientist, 29, 16-19, https://doi.org/10.1144/geosci2019-045, 2019.

Bono, R., Tarduno, J., and Singer, B.: Cretaceous magmatism in the High Canadian Arctic: implications for the nature and age of Alpha Ridge, EGU General Assembly, 2013, Vienna, Austria, 7-12 April 2013, EGU2013-11429, 2013.

Braun, V. and Clarke, V.: Using thematic analysis in psychology Using thematic analysis in psychology, Qual. Res. Psychol., 3, 77-101, https://doi.org/10.1191/1478088706qp063oa, 2006.

Dowey, N., Barclay, J., Fernando, B., Giles, S., Houghton, J., Jackson, C., Khatwa, A., Lawrence, A., Mills, K., Newton, A., Rogers, S., and Williams, R.: A UK perspective on tackling the geoscience racial diversity crisis in the Global North, Nat. Geosci., 14, 256-259, https://doi.org/10.1038/s41561-02100737-w, 2021.

Dutt, K.: Race and racism in the geosciences, Nat. Geosci., 13, 2-3, https://doi.org/10.1038/s41561-019-0519-z, 2020.

Kaaden, K. V., Ryan, C., Rivera-Valentín, E. G., Phillips, C. B., Haber, J., Filiberto, J., and Denton, A.: Creating Inclusive, Supportive, and Safe Environments in Planetary Science for Members of the LGBTQ+ Community, Bulletin of the AAS, 53, https://doi.org/10.3847/25c2cfeb.bf7d9e04, 2021.
Merrill, R. T., McElhinny, M. W., and McFadden, P. L. (Eds.): History of Geomagnetism and Palaeomagnetism, Chapter 1, in: The Magnetic Field of the Earth Paleomagnetism, the Core, and the Deep Mantle, Academic Press, 63, 1-14, ISBN: 978-0-12491245-8, 1998.

Migration Advisory Committee: Review of the shortage occupation list: 2020, Corporate report GOV.UK, https://www.gov.uk/government/publications/ review-of-the-shortage-occupation-list-2020 (last access: 24 February 2022), 2020.

National Risk Register: https://www.gov.uk/government/ publications/national-risk-register-2020, last access: 24 February 2022.

Núñez, A. M., Rivera, J., and Hallmark, T.: Applying an intersectionality lens to expand equity in the geosciences, J. Geosci. Educ., 68, 97-114, https://doi.org/10.1080/10899995.2019.1675131, 2020.

Paterson, G. A.: greigpaterson/Magnetic_to_the_Core_Survey: First Release, Version v1.0.0, Zenodo [data set], https://doi.org/10.5281/zenodo.6257839, 2022.

Torsvik, T. H., van der Voo, R., Preeden, U., Mac Niocaill, C., Steinberger, B., Doubrovine, P. V., van Hinsbergen, D. J. J., Domeier, M., Gaina, C., Tohver, E., Meert, J. G., McCausland, P. J. A., and Cocks, L. R. M.: Phanerozoic polar wander, palaeogeography and dynamics, Earth-Sci. Rev., 114, 325-368, https://doi.org/10.1016/j.earscirev.2012.06.002, 2012.

van der Boon, A.: Ten things you might not know about the Earth's magnetic field, ResearchGate, https://doi.org/10.13140/RG.2.2.17119.82089, 2019. 